\title{
CLINICAL PROFILE AND OUTCOME OF DENGUE HEMORRHAGIC FEVER IN A TERTIARY CARE HOSPITAL IN DHAKA
}

\author{
KHAN MOHAMMAD ARIF ${ }^{1}$, FAZLE RABBI MOHAMMED ${ }^{2}$, ZANNATUN NUR ${ }^{2}$, MD ZIAUSSHAMS ${ }^{3}$, MD. \\ BILLAL ALAM $^{4}$, MD. JULHASH UDDIN ${ }^{5}$, H A M NAZMUL AHASAN $^{6}$
}

\begin{abstract}
:
Background: Dengue has become endemic in Bangladesh since 2000. The cases are being encountered each year particularly in urban areas. Thus, Dhaka, Chittagong, Rajshahi, Khulna and other cities are commonly affected areas. We sought to get a profile of dengue hemorrhagic fever (DHF) in a tertiary care hospital in the Dhaka city.

Methods: This direct observational study was undertaken from June to October 2008 among the hospital admitted patients with a diagnosis of DHF.

Result: Out of 55 patients with DHF, $87.27 \%$ came from urban areas. About $43.64 \%$ patients showed various types of active bleeding in association with different clinical features. 100\% patients had relative bradycardia. Tourniquet test was positive in $43.63 \%$ patients. IgMand/or IgG antibody titer to dengue virus were positive in $85 \%$ cases.

Conclusion: The clinical picture of Dengue is not as diverse as other regions of the world and the National guideline is till now found to be effective in adequate management,
\end{abstract}

\section{Introduction:}

Dengue is endemic in 112 countries with an estimated 100 million cases per year. ${ }^{1}$ Each year, between 250,000 and 500,000 cases are reported as dengue hemorrhagic fever (DHF) due to the simultaneous presence of hemorrhagic manifestations, thrombocytopenia and signs of plasma leakage and at least 12,000 deaths occur worldwide. ${ }^{2,3}$ In Bangladesh, the magnitude of DF was largely unknown until an epidemic of DF and DHF broke out in June, 2000. Since then, it has become endemic here. ${ }^{4}$ Although serologic studies and virus isolation conducted during the outbreak of "Dacca fever" in 1964 revealed that the condition was due to dengue viral infection, sporadic cases and small outbreaks went unreported until it took heavy toll in 2000 (5,555 cases and 93 deaths); 2001 (2,430 cases and 44 deaths) and 2002 (6,104 cases and 58 deaths). ${ }^{5,6}$ To our knowledge, the study carried out in a tertiary care hospital in Khulna, Bangladesh in 2000 was the first one in this regard and they found a high fatality rate $(4.05 \%)$ from $\mathrm{DHF}$ and dengue shock syndrome (DSS). ${ }^{7}$ In our study, we aimed to evaluate the current trend of clinical manifestations and as well as the out come of DHF.

\section{Methods:}

This direct observational study was carried out in different medicine units of Dhaka Medical College Hospital from June to October, 2008. Total 55 patients with DHF were included. DHF was defined according to National guideline. Cases were divided into three age groups including group I (13 to 30 years), Group II ( 31 to 50 years) and group III ( 51 years and above). Location of residence in each case was recorded. All relevant symptoms and signs were recorded. Tourniquet test was done. Repeated total platelet count, packed cell volume and IgM and IgG antibodies for dengue virus were done. Other relevant investigations (e.g. complete blood count, Liver function test etc) were also performed to determine complications or to exclude differential diagnosis when required.

\section{Results:}

During the study period, a total 55 patients (46 male and 9 female) with DHF were reported. A total $69.09 \%$ patient placed in age group I, $27.27 \%$ in group II and $3.63 \%$ in group III. All of the patients came from urban (87.27\%) or semi urban (12.73\%) areas (Fig.-1).

1. Indoor Medical Officer, Department of Medicine, Dhaka Medical College \& Hospital. Dhaka.

2. Post-graduate Trainee, Department of Medicine, Dhaka Medical College \& Hospital. Dhaka.

3. Assistant Registrar, Medicine Unit - 3, Dhaka Medical College \& Hospital. Dhaka.

4. Associate Professor, Department of Medicine, Dhaka Medical College, Dhaka.

5. Professor, Department of Medicine, Shahabuddin Medical College, Dhaka.

6. Professor, Department of Medicine, Dhaka Medical College, Dhaka.

Correspondence: Dr. Fazle Rabbi Mohammed, House - 29, Road - 5, Dhanmondi, Dhaka. E-mail: drfazlerabbi@hotmail.com 


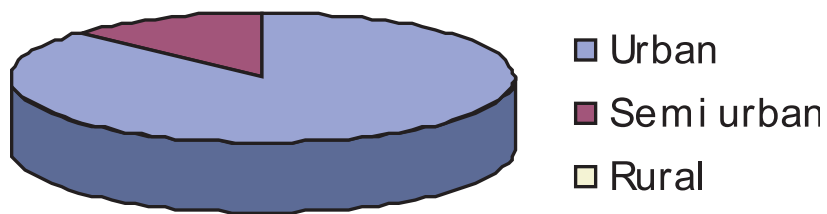

Fig.-1: Distribution of patients according to location. $(n=55)$

Regarding clinical manifestations, $>101^{\circ} \mathrm{F}$ temperature $(\mathrm{t})$ was recorded in all cases. $40 \%$ patients had a history of vomiting and $32.72 \%$ had headache, $45.45 \%$ had bodyache, $16.38 \%$ had eyeache and $12.7 \%$ had itching. Other features were had joint pain (9.09\%), loose motion (3.63\%), abdominal pain $(1.81 \%)$, anorexia $(5.45 \%)$ and shock (1.81\%). At least one of the features of active bleeding including gum bleeding, per vaginal or per rectal bleeding, black tarry stool, blood mixed vomiting, cough, bleeding per nose were present in $43.64 \%$ cases. Sub conjunctival haemorrhage was found in 9 (16.36\%) patients. Relative bradycardia was observed in all cases and $70.91 \%$ patients had low blood pressure.(Fig-2)

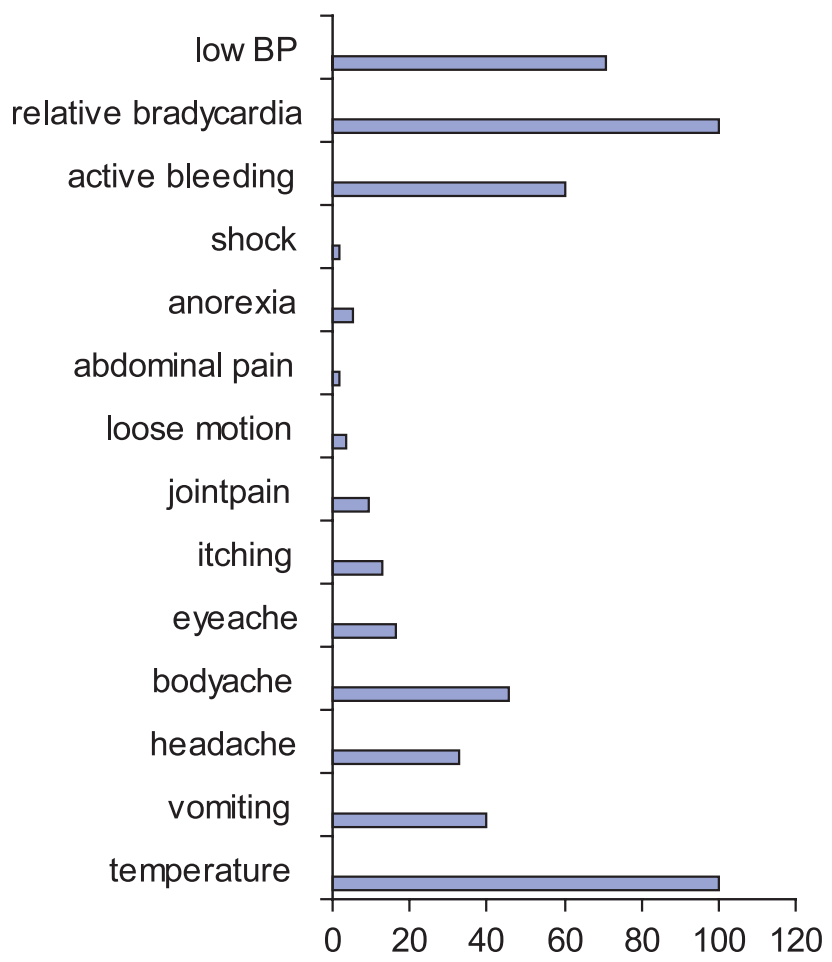

Fig.-2: Distribution of patients according to clinical features. $(n=55)$
Tourniquet test was positive in $43.63 \%$ cases. Total platelet count was found $<100,000 / \mathrm{cmm}$ in all patients. IgM and or IgG antibody titer to dengue virus were positive in $85 \%$ cases.

Majority of patients (50.9\%) presented with Grade I disease, 22(40\%) had Grade II, 4(7.25) had Grade III and only $1(1.81 \%)$ patient presented with Grade IV disease (Fig.-3).
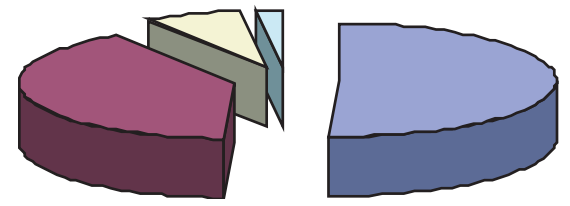

$\square$ Grade I

$\square$ Grade ॥

$\square$ Grade III

$\square$ Grade IV

Fig.-3: Distribution of patients according to grading of DHF. In our study, recovery rate was $100 \%$.

\section{Discussion:}

Dengue is a homonym for the African ki denga pepo, which appeared in English literature during an 182728 Caribbean outbreak. The first definite clinical report of dengue is attributed to Benjamin Rush in 1789. ${ }^{1}$ Since then, the incidence and clinical severity of dengue has increased dramatically. In South East Asia the mean number of annual cases of dengue haemorrhagic fever has increased from below 10000 in the 1950s and 60s to over 200000 in the $90 \mathrm{~s} .{ }^{8}$ The urbanization process, which has left many without adequate water, sewer systems or waste management, and created new breeding grounds for the vector, has hastened the spread of the disease. In urban areas, Aedes mosquitos breed on water collections in artificial containers such as plastic cups, used tires, flower pots, broken bottles, etc. Vector control has not halted the explosion in transmission of the disease. More rainfall in certain areas and warmer temperatures overall are providing optimal conditions for mosquitoes to spread the Dengue virus to breed and expand into new territories. ${ }^{9}$ In our study, most of the patients (87.27\%) came from urban areas.

Clinical features of DHF vary with the age of the patient. In our study, most of the patients were male and less than 31 years old. Dengue haemorrhagic fever is primarily a disease of children under 15 years but in our study, we include patients aged e" 13 years.

We found different clinical features including fever, vomiting, headache, bodyache, eyeache, itching, joint 
pain, loose motion, abdominal pain, anorexia, features of shock, gum bleeding (18.18\%), per vaginal bleeding (1.81\%), per rectal bleeding (3.63\%), black tarry stool (10.90\%), hematemasis (5.45\%), hemoptysis (1.81\%), epistaxis (1.81\%), conjuntival congestion, sub conjunctival haemorrhage, relative bradycardia and low blood pressure. These features are consistent with typical cases of dengue fever but some percentage of different manifestation differs from studies performed by Abu Bakar and Ahasan $\mathrm{H} \mathrm{A} \mathrm{M} \mathrm{N} \mathrm{in} \mathrm{khulna}{ }^{7}$ in 2000 and Celia C. Carlos et. al. ${ }^{10}$ or Ole Wichmann et. al. ${ }^{11}$ Relative bradycardia has been reported in many infectious diseases, including typhoid fever, Legionnaires' disease, psittacosis, typhus, leptospirosis, malaria, and babesiosis. ${ }^{12,13}$ During 2005 a case-control study in Singapore observed relative bradycardia in several patients with dengue fever. ${ }^{14}$ In our study we found relative bradycardia in cent percent cases. Although DHF manifests many neurological features including headache, seizure, depressed sensorium, neck stiffness, paralysis, cranial nerve palsies, coma and liver or renal failure for more than a century, we did not find any such case.

In this study, $43.64 \%$ patients had active bleeding of which gum bleeding was the commonest presentation. Tourniquet test was positive in $43.63 \%$ patients which were significantly lower than a study done in 2001 in Thailand (76\%). ${ }^{11}$ Different studies depict unpredictable sites of active bleeding.

IgM and or IgG antibody titer to dengue virus were positive in $85 \%$ cases, which was higher (60.73\%) than a study done by Ole Wichmann et. al. ${ }^{15}$

As we collected data from a reputed tertiary level hospital where treatment facilities were satisfactory and most of the patients came here without delay, marked complications or bleeding manifestation were less. Moreover, none of our patients died nor had any long term squelae.

The fatality rate in patients who met criteria for dengue hemorrhagic fever or dengue shock syndrome was approximately 6\% in 1997 Cuban epidemic. ${ }^{16}$ Another study showed $0.46 \%$ case fatality rate in DHF. ${ }^{11}$ A study in Singapore revealed $5.4 \%$ fatality rate in DHF in adults during an epidemic in $2004 .{ }^{17}$ Fatality rate was found $4.05 \%$ from DHF and DSS in the study done by Abu Bakar and Ahasan HAMN et. al. in Khulna, Bangladesh in 2000. ${ }^{7}$ This improvement in survival rate in our study might be a reflection of awareness among people of Dengue in the recent years resulting in early self reporting. In addition, a welldeveloped National Guideline is established since 2000, which is found completely effective in proper management of patients.

\section{References:}

1. Price DD, Wilson SR. Dengue Fever. emedicine. Updated: Jan 31, 2008.URL:http://emedicine. medscape.com/article/781961-overview.Accessed $21^{\text {st }}$ January 2009

2. Gubler DJ. Epidemic dengue/dengue hemorrhagic fever as a public health, social and economic problem in the 21st century. Trends Microbiol 2002; 10: 100-3.

3. World Health Organization. Scientific Working Group on Dengue. Meeting report, Geneva, Switzerland, 3-5 April 2000. Special Programme for Research and Training in Tropical Diseases, 2000. 11 p. In: http://www.popline.org/docs/1380/ 158581.html. Accessed 16 December, 2008.

4. ICDDRB Annual Report, 2001. Bangladesh Dengue Website. In: http://www.geocities.com/prevent_ dengue/. Accessed 16 December, 2008

5. Aziz MA, Graham RR, Gregg MB.” Dacca fever" An outbreak of dengue.Pak j Med Res1967;6:83-92

6. World Health Organization. Dengue fever and dengue haemorrhagic fever. In: http:// www.whoban.org/communicable_dis_dengue.html. Accessed 26 January, 2009.

7. Bakar A, Ahsan HAMN, Ahsan M, Mamun AA, Karim SR. Emergence of Dengue in Bangladesh. PAFMJ 2004;54(2):147-50.

8. Gibbons RV, Vaughn DW. Dengue: an escalating problem.BMJ 2002;324:1563-1566

9. Barclay E. Climate Change Spurring Dengue Rise, Experts Say. National Geographic News 2007 Sep 21.URL: news.nationalgeographic.com/news/2007/ 09/070921-dengue-warming.html

10. Carlos CC, Oishi K, Cinco MDD, et. al. Comparison of clinical features and hematologic abnormalities between dengue fever and dengue hemorrhagic fever among children in the philippinesam. J. Trop Med Hyg 2005; 73: 435-440.

11. Wichmann O, Hongsiriwon S, Bowonwatanuwong C, et. al. Risk factors and clinical features associated with severe dengue infection in adults and children during the 2001 epidemic in Chonburi, Thailand. Tropical Medicine and International Health 2004; 9:1022-1029. 
12. Ostergaard L, Huniche B, Andersen PL. Relative bradycardia in infectious diseases. J Infect. 1996;33:185-91.

13. Cunha BA. The diagnostic significance of relative bradycardia in infectious disease. Clin Microbiol Infect. 2000;6:633-4. Wichmann O, Gascon J, Schunk M. Severe Dengue Virus Infection in Travelers: Risk Factors and Laboratory Indicators. JID 2007; 195:1089-96.

14. Lateef A, Fisher DA, Tambyah PA. Dengue and Relative Bradycardia. Emerging Infectious Diseases 2007;13(4):650-651.
15. Wichmann O, Gascon J, Schunk M. Severe Dengue Virus Infection in Travelers: Risk Factors and Laboratory Indicators. JID 2007; 195:1089-96.

16. Shepherd SM, Hinfey PB, ShoffWH. Dengue Fever. Updated: Nov 26, 2007. In: http://emedicine. medscape.com. Accessed 1 January, 2009.

17. Ong A, Sandar M, Chen M, Sin L. Fatal dengue hemorrhagic fever in adults during a dengue epidemic in Singapore. International Journal of Infectious Diseases 2003; 11: 263 - 267. 